\title{
RAZONABILIDAD, CORRECCIÓN MORAL Y COTO VEDADO
}

\author{
Silvina Álvarez \\ Universidad Autónoma de Madrid
}

RESUMEN. En el artículo «¿Puede la razonabilidad ser un criterio de corrección moral?» Ernesto Garzón Valdés analiza cuáles son los límites a los contenidos de la ética normativa, centrándose para ello en la noción de razonabilidad. En el presente escrito, y tras realizar una breve síntesis de los argumentos del autor, se indaga en la conexión entre la razonabilidad y el coto vedado, así como en las posibilidades de validar los valores morales a través de la razonablidad. La vía negativa propuesta por Garzón, es decir, la posibilidad de definir los contenidos morales partiendo de lo radicalmente malo, es examinada a la luz de las dificultades que esta vía no resuelve cuando se trata de afrontar cuestiones de fundamentación. Finalmente, se realizan algunas consideraciones sobre los objetivos del artículo analizado en el ámbito de los debates actuales en filosofía moral y política.

Palabras clave: Ernesto Garzón Valdés, razonabilidad, corrección moral.

ABSTRACT. The article «¿Puede la razonabilidad ser un criterio de corrección moral?» by Ernesto Garzón Valdés, analyzes the limits to the contents of normative ethics, and focuses on the concept of reasonableness. Besides, Garzón proposes a «negative way» to determine moral contents on the basis of radically evil. This paper examines the problems the negative way does not remove as regarding questions of moral foundations, and points out the aims of Garzón's article in the context of contemporary debates on moral and political philosophy.

Keywords: Ernesto Garzón Valdés, reasonableness, moral correction. 
os escritos de Ernesto GARZÓN VALDÉs se caracterizan por la claridad expositiva, el uso de una terminología precisa y singular y una estrategia argumental sugerente y persuasiva. Muestra de todo esto es su artículo «¿Puede la razonabilidad ser un criterio de corrección moral?» ${ }^{1}$, en el que una vez más aparece su preocupación constante, en materia moral, en torno a los contenidos de la ética normativa.

Para dar respuesta a la pregunta respecto de si puede la razonabilidad servir para determinar los contenidos de la moral o, en otras palabras, si puede ser un criterio de corrección moral, GARZÓN argumenta a lo largo de 20 apartados, presentando en cada uno de ellos tesis concretas para avanzar en su línea argumental. De manera muy esquemática dichas tesis son las siguientes:

1. «Supuesto de la ignorancia querida»: debemos renunciar a la aspiración del conocimiento total (1998b: 146).

2. «Postulado de simetría»: la admisión de enunciados morales debe estar sujeta a la imparcialidad (1998b: 148).

3. «Postulado del puente»: la argumentación moral debe estar basada sobre la racionalidad —y las razones puente servirían para su comprensión- (1998b: 148).

4. «Tesis del solapamiento parcial de los juicios morales y los juicios empíricos» (1998b: 150).

5. «Prohibición del imperialismo de los criterios de corrección» o no aplicación de los criterios de validez de algunos ámbitos científicos a otros ámbitos del conocimiento (1998b: 152).

6. «Criterio de razonabilidad» como criterio para la validación de los postulados morales (1998b: 152).

7. «Tanto la teoría de RAWLS como la de BARRY aplican el criterio de la razonabilidad como criterio de corrección de justicia política para sociedades multiculturales pero homogéneas en el sentido de que sus miembros están dispuestos a renunciar a la imposición de sus concepciones de lo bueno a fin de lograr una paz social razonable. Ambas teorías pretenden ser neutrales con respecto a las diferentes concepciones razonables de lo bueno» (1998b: 156).

8. En algún sentido lo razonable depende del contexto en que se argumenta.

9. Desde otra perspectiva, y siguiendo a GAUs, la razonabilidad no debería depender de las personas sino de pautas sobre lo razonable.

10. Pero si la posibilidad de razonabilidad depende de que las personas respeten los principios de igualdad y libertad y no impongan sus propias concepciones valorativas, en consecuencia la razonabilidad presupone una concepción de lo bueno.

11. «Parecería entonces que el ámbito de lo razonable está enmarcado por el coto vedado y razonable querría decir tan solo aquello que los agentes acuerdan respetando el coto vedado. Si ello es así, la razonabilidad, como criterio de corrección, es un criterio débil dependiente del coto vedado» (1998b: 158).

12. La neutralidad no puede existir sino basándose en enunciados morales o prudenciales comprometidos.

\footnotetext{
${ }^{1}$ GARZÓN VALDÉS, 1998b. Una versión anterior del mismo trabajo se publicó con el título «Razonabilidad y corrección moral», en GARZÓN VALDÉS, 1998a.
} 
13. Resulta dudoso que la tolerancia social pueda basarse en la neutralidad.

14. Frente a la inseguridad que existe en el ámbito normativo para determinar qué es lo bueno, puede resultar más seguro considerar qué es lo malo.

15. Hace falta sentar las condiciones para explorar la vía negativa de lo malo e identificar lo radicalmente malo.

16. A pesar del argumento agustiniano - lo malo es la negación de lo buenoresulta más fácil el consenso sobre lo malo que sobre lo bueno.

17. También existe consenso en torno al concepto de daño.

18. «Podría recurrirse al concepto de irrazonabilidad como criterio de incorrección» (1998b: 163).

19. «La irrazonabilidad funcionaría de manera similar a la falsabilidad en las ciencias naturales, sirviendo de límite a lo “meramente racional” (1998b: 164).

20 y 21. «Con las salvedades y recaudso aquí expuestos, es posible dar una respuesta afirmativa a la pregunta: “¿puede la razonabilidad ser un criterio de corrección moral?” $(1998 \mathrm{~b}: 165)$.

$\mathrm{El}$ argumento central de este trabajo es que cualquier defensa de lo razonable como criterio de corrección moral debe estar condicionada a la aceptación de una teoría del bien, en la medida que la idea misma de razonabilidad depende de ella; y tal teoría del bien, según GARZÓN, se construye en torno a lo que él ha dado en llamar «coto vedado» o conjunto de valores últimos. Detrás de la noción de razonabilidad que se propone hay, por tanto, una concepción moral fuertemente universalista y claramente definida en cuanto a su contenido - los valores, derechos o libertades contenidos en el coto vedado-. Ahora bien, si la corrección moral sólo depende de la noción de razonabilidad en la medida en que ésta respete el contenido moral mínimo que exige el coto vedado, entonces es el propio coto vedado el que funciona como límite a la corrección moral. Esto plantea la importante cuestión en torno a cuáles son los criterios de corrección no ya para otras posibles teorías del bien, sino para el coto vedado como meta-teoría del bien.

No escapan al autor las dificultades que acechan a la justificación de cualquier conjunto de valores respecto de los cuales se predica su validez universal. Y es por ello que propone la vía negativa: indagar en la justificación no ya de los valores — positivoscuya corrección se postula, sino en aquello que por radicalmente malo, por irrazonable, se debe excluir. No resulta del todo claro, sin embargo, si la vía negativa serviría para determinar lo razonable —o lo irrazonable — siempre dentro del límite fijado por el contenido del coto vedado, o si en cambio se presenta como vía para determinar el contenido del propio coto vedado, o ambas cosas.

En cualquier caso, el camino hacia la justificación lo transita GARZÓN a través de una propuesta racionalista matizada, en la que la idea de razonabilidad viene en auxilio de las insuficiencias que presenta la mera racionalidad. Propone entonces el criterio de razonabilidad como el recurso que dotaría la teoría moral con un carácter científico, en el sentido de dotarla de objetividad (1998a: 21; 1998b: 156). Tras rechazar la razonabilidad como la entienden RAWLS (1993) o BARRY (1995), propone, como hemos señalado ya, llegar al criterio de razonabilidad por la vía negativa, por la vía de lo irrazonable. Por irrazonable entiende aquello «que afecta básicamente a la supervivencia de la especie humana», todo aquello que por ser radicalmente malo «impide la realiza- 
ción de todo plan de vida» (1998a: 24). La propuesta de GARZÓN recoge, creo, una intuición extendida respecto de la noción de humanidad o dignidad humana cuyo mínimo moral rechaza aquello que es radicamente malo o que impide el desarrollo de las capacidades humanas (1998b: 162-165).

La vía negativa, sin embargo, no está exenta de problemas - como reconoce el propio autor al señalar la objeción agustiniana-. La definición de lo irrazonable puede presentar dificultades similares a la definición de lo razonable. En primer lugar, no basta con estipular que dañar a otro es esencialmente malo, sino que hay que fijar cuál es el alcance del concepto de daño. Tampoco parece suficiente, a este respecto, apelar a sensaciones subjetivas de las personas, ya que en este terreno podríamos tropezar con diferencias significativas. Por otra parte, no parece que exista acuerdo respecto de cuál es el alcance que debemos dar al concepto de daño, y aunque se trate de un concepto central de la teoría moral y política - como ejemplo baste señalar el importante papel que juega en la teoría de la libertad de MiLl (1859-1970)_, importantes divergencias surgen al momento de identificar su contenido sustantivo.

Otro problema que subyace a la vía negativa — como a la positiva — tiene que ver con las premisas subyacentes cuya justificación es dejada de lado. Así, si afirmamos que lo malo es aquello que impide la supervivencia o la realización de un plan de vida, subyacen a estas premisas presupuestos morales fuertes, de contenido sustantivo, como el que afirma el valor supremo de la vida o de la autonomía personal, y entonces necesitaremos ulteriores fundamentaciones de estos valores subyacentes. En otras palabras, si lo irrazonable -o lo razonable - presuponen otros principios, éstos necesitan ser fundamentados previamente $-\mathrm{y}$ no basta con afirmar su razonabilidad para justificarlos-. Si, en cambio, lo razonable se basa en un «solapamiento de los juicios morales y los juicios empíricos» (GARZÓN, 1998a: 20), esto tiene otros problemas. Una cosa es afirmar que los juicios morales se obtienen, en parte, de enunciados empíricos — de la observación de hechos empíricos (ver HARE, 1999) — y otra afirmar que su verdad coincide con la verdad de los juicios empíricos, como si los hechos empíricos fuesen portadores de verdad moral. Siguiendo a P. DASGUPTA (1993), GARZÓN parece derivar la categoría de «mal radical» de algunos hechos vinculados al sufrimiento o el malestar de las personas. Sin embargo, conferir valor moral a un hecho requiere en cualquier caso de una justificación o fundamentación no empírica y no parece probado que el sufrimiento sea en todos los casos portador de reprobación moral.

Al final, y aunque el propósito de GARZÓn no es trazar las bases de una teoría de fundamentación moral sino acotar los límites infranqueables de la teoría del bien que propone - a partir de la noción de coto vedado—, no parece que lo primero pueda hacerse sin lo segundo. Es así que el trabajo deja planteadas cuestiones importantes sobre el alcance del objetivismo tal como parece revelarse en la propuesta del coto vedado. La adhesión a una vía fuertemente kantiana de razonamiento moral abre también algunos interrogantes sobre cómo resolver los problemas que presenta la propia vía del objetivismo racionalista (sobre objetivismo moral, ver ÁLVAREZ, 2002).

Más allá de estas observaciones, el objetivo que subyace a la argumentación del autor, que acepta la noción de razonabilidad pero la condiciona a una teoría del bien que le sirve de límite, es el de contener las éticas que más o menos vecinas al relativismo, amenazarían con debilitar esa teoría del bien o coto vedado. Se trataría de evitar que la 
vía de lo razonable pueda servir para validar demasiadas concepciones de lo bueno, incluso aquellas que puedan entrar en conflicto con el coto vedado. Algunas formulaciones del multiculturalismo - y digo algunas ya que la teoría moral y política del multiculturalismo ha tenido en los últimos años desarrollos muy diversos que van en direcciones teóricas a veces opuestas a pesar de englobarse bajo el rótulo, ya demasiado vago, de multiculturalismo-, amenazarían los valores —universales u objetivosdel coto vedado, tergiversando de este modo el significado de la razonabilidad como criterio que lejos de admitirlo todo debe servir de control de contenidos sustantivos preestablecidos. De manera similar a como, en otro importante trabajo, define la tolerancia (ver GARZÓN, 1993), GARZÓN procede a definir lo razonable como criterio que solo sirve si hay un sistema moral de referencia que hace que sea razonable $-\mathrm{o}$ tolerable- aquello que está dentro de sus límites.

Creo que este artículo, como tantos otros del autor, deja planteadas cuestiones importantes sobre el alcance de los valores, su universalidad y sus posibilidades de fundamentación, y presenta diversas vías para el análisis y la reflexión filósófica. Solo me resta agradecer a Ernesto GARZÓN VALDÉS, por su trabajo.

\section{BIBLIOGRAFÍA}

Álvarez, S., 2002: La racionalidad de la moral, Madrid: Centro de Estudios Políticos y Constitucionales.

BARRY, B., 1995: Justice as Impartiality, Oxford: Clarendon Press.

GARZÓN VALDÉs, E., 1993: «No pongas tus sucias manos sobre Mozart», en Derecho, ética y política, Madrid: Centro de Estudios Constitucionales, pp. 401-415.

- 1998a: «Razonabilidad y corrección moral», Claves de razón práctica, 88: pp. 18-26.

- 1998b: «Puede la razonabilidad ser un criterio de corrección moral», Doxa, 21 (2): pp. 145166.

HARE, R. M., 1999: Ordenando la ética (traducción castellana de J. VerGÉs GIFRA), Barcelona: Ariel.

MiLL, J. S., 1859-1970: Sobre la libertad (traducción al castellano de P. DE AZCÁRATE), Madrid: Alianza.

RawLS, J., 1993: Political Liberalism, New York: Columbia University Press. 